\title{
Hypoglycemic, Antitussive and Analgesic Effects of Nanoparticles of Cordia myxa Fruits Extract
}

\author{
Shokooh Salimimoghadam ${ }^{1}$, Ali Ashrafi ${ }^{2}$, Fakhri Kianidehkordi' ${ }^{1}$, Hossein Najafzadehvarzi ${ }^{1,3 *}$ \\ 'Department of Pharmacology, Faculty of Veterinary Medicine, Shahid Chamran University of Ahvaz, Khuzestan Province, IRAN \\ ${ }^{2}$ Department of Materials Engineering, Isfahan University of Technology, Isfahan Province, IRAN. \\ ${ }^{3}$ Cellular and Molecular Biology Research Center, Health Research Institute, Babol University of Medical Sciences, Babol, IRAN.
}

\begin{abstract}
Background: Cordia myxa is a plant from Boraginaceae family and has many useful therapeutic properties. Aim of the study is to compare the pharmacological efficacy of Cordia myxa hydro-alcoholic extract (Bulk Extract [BE]) and nanoparticles of hydro-alcoholic extract (NPE) including hypoglycemic, antitussive, anti-inflammatory and analgesic activity. Methods: Hydro-alcoholic maceration extract of dry fruits was powdered to nanoparticle size by ball-milling technique. Hyperglycemia and cough were induced in mice by alloxan $(120 \mathrm{mg} / \mathrm{kg}$, i.p.) and ammonia, respectively. Inflammatory and analgesic evaluations of extracts were carried out with the formalin-induced edema in the mice paw and acetic acid tests. NPE and BE were administrated at single dose $(750 \mathrm{mg} / \mathrm{kg}$, i.p.). Positive control group was received dextromethorphan (10 mg/kg, orally) in cough and indomethacin (25 mg/kg, orally) for analgesic models. Blood glucose level, the number of coughs and writhes and duration of foot lickings were calculated. Results: The blood glucose did not statistically reduce by extracts. Both extracts could significantly inhibit the frequency of cough and
\end{abstract}

dramatically reduce the duration of paw licking. NPE could significantly reduce writhes. Conclusion: We concluded that extracts had no hypoglycemic activity. Both extracts created therapeutic activities better than dextromethorphan. NPE exerted better anti-inflammatory and analgesic activity compared to $\mathrm{BE}$

Key words: Anti-inflammatory, Analgesic, Antitussive effects, Cordia myxa, Nanoparticles.

\section{Correspondence}

Prof. Hossein Najafzadehvarzi ${ }^{1,2}$

'Department of Pharmacology, Faculty of Veterinary Medicine, Shahid Chamran University of Ahvaz, IRAN.

${ }^{3}$ Cellular and Molecular Biology Research Center, Health Research Institute, Babol University of Medical Sciences, Babol-47134, Isfahan Province, IRAN.

Phone no: +989166182496

Email: najafzadehvarzi@gmail.com

DOI: 10.5330/ijpi.2019.4.38

\section{INTRODUCTION}

Cordia myxa (C. myxa) fruit is used in folk medicine as a calmative rheumatic pain, an anthelmintic and antihelminthic. Mucilage of C. myxa has anti-leishmanial effects ${ }^{1,2}$ and antiradical capacity. ${ }^{3,4}$ In some studies, for C. myxa it was suggested that its mucilage could decrease rabbit blood pressure and stimulated the respiratory rate. ${ }^{5}$ The aqueous C. myxa extract stimulated cell mediated and immune responses in mice. ${ }^{6}$ The ethanolic extract of C. myxa fruits reduced lympho-proliferation and inhibited (without cytotoxicity) the percentage of PMNLs forming Formazan granules in vitro immune-modulating test. ${ }^{7}$ Recent pharmacological studies have demonstrated that different extracts of C. myxa also have some properties like protective effect against doxorubicin-induced cardiotoxicity ${ }^{8}$ and liver fibrosis ${ }^{9}$ and hepatoprotective effect. ${ }^{10}$ Also, antimicrobial effects of C. myxa were studied. ${ }^{11,12}$

The C. myxa has bronchodilator property probably affects via nitric oxide process. ${ }^{13}$ In a study on hydro-alcoholic extract of C. myxa fruit it was shown that the extract has analgesic and anti-inflammatory properties in formalin test and acetic acid tests. ${ }^{14}$ The C. myxa extract have been show nociceptive effect in hot plate test and increased the reactive time to the thermal stimuli. ${ }^{15}$ The anti-inflammatory effects of C. myxa fruit was demonstrated in acetic acid induced colitis in rats. ${ }^{16}$

Nanotechnology is a branch of technology that attracted much attention today and can be used for improving methods of treatments and diagnosis related to the human and even animal's health. ${ }^{17,18}$ Nanoparticles have a high surface to size. ${ }^{19}$ Because of small size of nanoparticles, they can cross easily through barriers. ${ }^{20}$ Nanoparticles have a conjugating surface. They can be used for medical purposes, drug delivery, tumor detection and diagnostic imaging. ${ }^{20-23}$ Thus, the aim of this study was to validate and making a comparison between efficacy of nanoparticle and bulk hydro-alcoholic extract of C. myxa fruits in pharmacological tests; hypoglycemic, antitussive, anti-inflammatory and analgesic activities in experimental and animal modeling.

\section{MATERIALS AND METHODS}

\section{Animals}

For the present study, we used male and female albino mice weighing 18-22 g were obtained from the animal research center of Jundishapour University of Ahvaz. Animal experimentation protocols conformed to the institutional animal ethics committee's guidelines (EE/97.24.3.49684/ scu.ac.ir). This experimental study was conducted in veterinary medicine faculty, Shahid Chamran University of Ahvaz, Iran. Animals were housed in cages under $12 \mathrm{hr}$ light-dark cycle conditions at room temperature and were fed with standard pellet die and had free access to water and food. Mice were divided into groups randomly.

\section{Preparation of Extract and Administration}

The powder of fruits was extracted using maceration with ethanol. The powdered fruits were macerated in $70 \%(\mathrm{v} / \mathrm{v})$ ethanol $(5: 10 \mathrm{w} / \mathrm{v})$ at room temperature for $72 \mathrm{hr}$. Then, it was shaken for $4 \mathrm{hr}$. The mixture was filtered with Buchner funnel and Whatman filter paper No.1. The resulting extract concentrated under pressure using a rotary evaporator in $40^{\circ} \mathrm{C}$. 
Next, the extract was powdered with freeze dryer. ${ }^{24}$ The yield (w/w) of extract was $34.7 \%$. The extract was stored at refrigerator for future studies. The hydro-alcoholic extract (bulk extract) and nanoparticles of powdered hydro-alcoholic extract were administrated at single dose (750 $\mathrm{mg} / \mathrm{kg}$, i.p.). For tests the extracts were suspended with normal saline. There were not any toxicity properties for this dose based on a preliminary experiment (data not showed). Normal saline was taken as control.

\section{Preparation of Nano Particle Size of Extract}

The hydro-alcoholic extract powders were cryomilled in the liquid nitrogen using the zirconia balls at $-50^{\circ} \mathrm{C}$ using a home-made attritor. The ball to powder ratio was $25: 1$ and the attrition speed was $250 \mathrm{rpm}$. The resulting mixture has been dried in an oven at $50^{\circ} \mathrm{C}$ for $12 \mathrm{hr}^{25}$ In this paper, for determination nanoparticles size, the Scanning Electron Micrographs (SEM) of the Nano extract (Figure 1), was prepared in Isfahan University of Technology, Isfahan, Iran.

\section{Hypoglycemic study}

Diabetes mellitus was induced by alloxan (Sigma Aldrich) $120 \mathrm{mg} / \mathrm{kg}$ body weight. ${ }^{26}$ Thirty minutes prior to injection of alloxan, mice were treated with extracts. Blood glucose levels of mice were measured with glucometer (On Call Plus blood glucose meter, Germany) before treatment and subsequently at 1,2 and $3 \mathrm{hr}$ after treatment with extracts. Mice with blood glucose level more than $250 \mathrm{mg} / \mathrm{dl}$ were considered as diabetic. Three groups of mice were used. Control received normal saline (orally). Group two and three received Nanoparticle of Extract (NPE) and bulk extract (BE) $\left(750 \mathrm{mg} / \mathrm{kg}\right.$, i.p.), ${ }^{27}$ respectively.

\section{Antitussive study}

Antitussive effects of extracts were measured by Murine method of ammonia induced cough as described before. Mice were numbered and divided into 4 groups. Twenty minutes after administration of extracts (750 mg/kg, i.p.), ${ }^{27}$ mice were individually placed into a $500 \mathrm{ml}$ wide mouth clear glass chamber, exposed to $1 \mathrm{ml} 5 \% \mathrm{NH}_{3}$ (loaded in cotton) and the number of cough was counted during $2 \mathrm{~min}$ and then $5 \mathrm{~min}$ out of the chamber. For scoring purposes, a typical cough is indicated by contraction of abdominal cavity and subsequently opening of the mouth accompanying with sound of cough. Control groups treated with normal saline (orally) and dextromethorphan (Alhavi Pharmaceutical Company) $\left(10 \mathrm{mg} / \mathrm{kg}\right.$, orally) as reference drug. ${ }^{28}$

\section{Anti-inflammatory and analgesic study}

Formalin test: Groups of 8 mice were used. The inflammation was produced by subcutaneous injection of $0.04 \mathrm{ml} 2.5 \%$ formalin in the plantar surface of right hind paw. ${ }^{29}$ The extracts $(750 \mathrm{mg} / \mathrm{kg})$ were administrated intraperitoneally and after 20 min formalin was injected. ${ }^{27}$ The duration of paw licking was measured by chronometer in 5 (acute phase) and 15-25 (chronic phase) min after formalin administration as acute and chronic phase, respectively. Control group received normal saline (orally). Indomethacin (25 mg/kg, orally) was used as reference drug. ${ }^{16}$

Acetic Acid Test: Mice were divided into groups of 8 mice for control and test. The extracts $(750 \mathrm{mg} / \mathrm{kg})$ were administrated $20 \mathrm{~min}$ prior to the acetic acid solution $1 \% \mathrm{v} / \mathrm{v}(0.3 \mathrm{ml}$, i.p. $)$ injection. ${ }^{27}$ The mice were individually placed into a stainless steel lab tray dish. The number of writhes produced in mice was counted in first and third $10 \mathrm{~min}$ after acetic acid injection. Stretching of the abdomen and at least one of the hind paws was considered as a writhe. Control received normal saline (orally) and indomethacin $(25 \mathrm{mg} / \mathrm{kg} \text {, orally })^{16}$ was administrated as reference drug. ${ }^{29}$

\section{Statistical analysis}

The obtained data were analyzed using SPSS Statistic software (version 17 , USA) by $t$ test, ANOVA and LSD tests or repeat measure. Results are expressed as mean \pm standard error (S.E.M). $P$ value was considered significant when $P<0.05$.

\section{RESULTS}

The mean of blood glucose level were calculated (Table 1). There was no significant difference between groups and times. Only it was seen unexpected fluctuations in bulk group.

In order to evaluate the antitussive activity of NPE and BE mice cough model induced by ammonia are used. The effect of extracts on ammonia induced cough is shown in Figure 2. The mean of cough number was

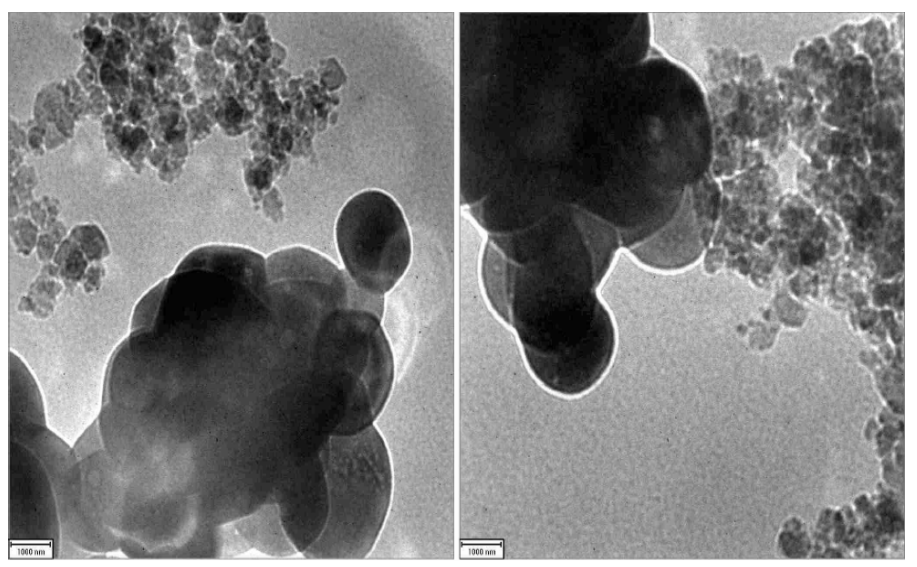

Figure 1: Scanning electron microscope (SEM) images of the nanoparticles of Cordia myxa fruits extract.

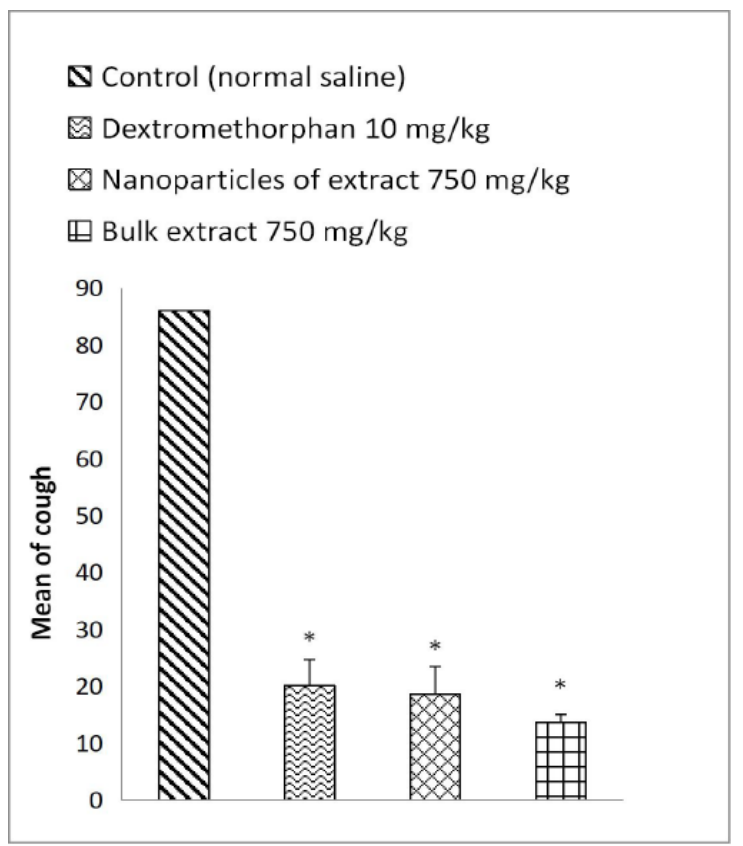

Figure 2: Effect of intraperitoneally injected Cordia myxa fruits nano particle and bulk hydroalcoholic extracts on ammonia-induced cough test in mice. The cough was produced by putting the mice into a glass chamber exposed to $1 \mathrm{ml} 5 \% \mathrm{NH}_{3}$ (loaded in cotton). The number of cough was counted 2 and 5 $\mathrm{min}$ in and out of the chamber, respectively. Values are mean \pm S.E.M of cough number. ${ }^{*} P<0.0001$, compared to control. 
measured 86 in control. The mean of cough was significantly decreased to $18.67 \pm 4.807$ and $13.67 \pm 1.358$ by NPE and BE in group 3 and 4 , respectively. There was a significant difference between group 3 and 4 compared to control $(P<0.0001)$. But there was any significant difference between NPE group compared to BE administrated group $(P=0.377)$. Extracts are nearly more effective than that of dextromethorphan. But there were no significant difference between their effects. Dextromethorphan decreased the frequency of cough to $20.17 \pm 4.52$ and it was significant compared to control $(P<0.0001)$.

The mean of paw licking time (s) in the acute phase (0-5 min) after formalin injection in the group 1 to 4 were $65.6,58.5,28.67$ and $50.33 \mathrm{sec}$, respectively on formalin test (Figure 3 ). The NPE exhibit significant antiinflammatory activity compared to control $(P=0.021)$. The mean of paw licking time (s) in chronic phase (15-25 min) after formalin injection in group 1 to 4 were $74.4,4.33,0$ and $6.17 \mathrm{sec}$, respectively. Indomethacin as well as the NPE and the BE showed significant anti-inflammatory activ- ity $(P<0.0001)$. NPE and BE administrated groups did not demonstrated significant difference $(P=0.061)$ (Figure 4$)$.

The bulk and nano particle of extract of C. myxa fruits significantly reduced the number of writhes induced by a $1 \%$ acetic acid solution. The mean of writhing numbers in the acetic acid test in the first $10 \mathrm{~min}$ after acetic acid injection was $38.4,22,26.33$ and 47.0 writhes/10 min in the groups, respectively. The NPE significantly reduced the number of mice abdominal constrictions compared to control $(P=0.048)$ and $\mathrm{BE}$ $(P=0.002)$ (Figure 5).

The mean of writhing numbers in mice in third $10 \mathrm{~min}$ after acetic acid injection was $20.4,0.7,20.33$ and 32.8 writhes/10 $\mathrm{min}$, respectively. The bulk extract of fruits showed significant differences but no significant anti-inflammatory activity compared to control $(P=0.026)$. The NPE showed no significant anti-inflammatory activity compared to control in the third min after intraperitoneally acetic acid injection $(P=0.989)$ but it exhibit a significant reduce in the number of abdominal stretching rather than $\mathrm{BE}(P=0.021)$ (Figure 6).

\begin{tabular}{|c|c|c|c|c|c|}
\hline \multirow[b]{2}{*}{ Group } & \multirow[b]{2}{*}{ Treatment } & \multicolumn{4}{|c|}{ Average of blood glucose level (mg/dl) } \\
\hline & & $0^{\text {th }}$ hour & $1^{\text {st hour }}$ & $2^{\text {nd }}$ hour & $3^{\text {rd }}$ hour \\
\hline I & Normal saline & 600 & $561.6 \pm 13.46$ & $526.6 \pm 34.26$ & $525.4 \pm 55.47$ \\
\hline II & $\begin{array}{c}\text { Nanoparticle of } \\
\text { extract }\end{array}$ & $533 \pm 41.98$ & $561.6 \pm 13.46$ & $551.4 \pm 34.08$ & $525.4 \pm 55.47$ \\
\hline III & Bulk extract & $379 \pm 64.00$ & $501 \pm 17.62$ & $381.33 \pm 69.90$ & $422.5 \pm 50.50$ \\
\hline
\end{tabular}

Values are the mean \pm S.E.M of blood glucose in diabetic mice, compared to control (normal saline).

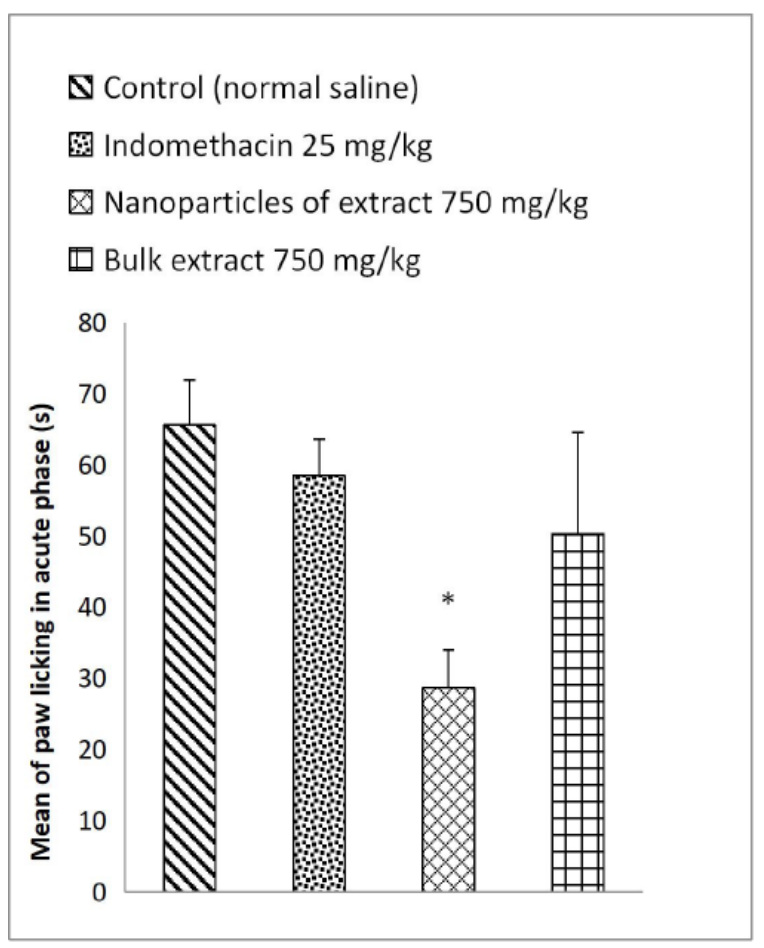

Figure 3: Effect of fruit Cordia myxa nano and bulk hydro-alcoholic extracts on formalin induced inflammation in hind paw of mice. The inflammation was produced by subcutaneous injection of $0.04 \mathrm{ml}$ of $2.5 \%$ formalin in the right hind paw of the mice. Values represent the mean \pm S.E.M of duration of paw licking in $5 \mathrm{~min}$ after treatments as acute phase of inflammation, ${ }^{*} P<0.021$, compared to control.

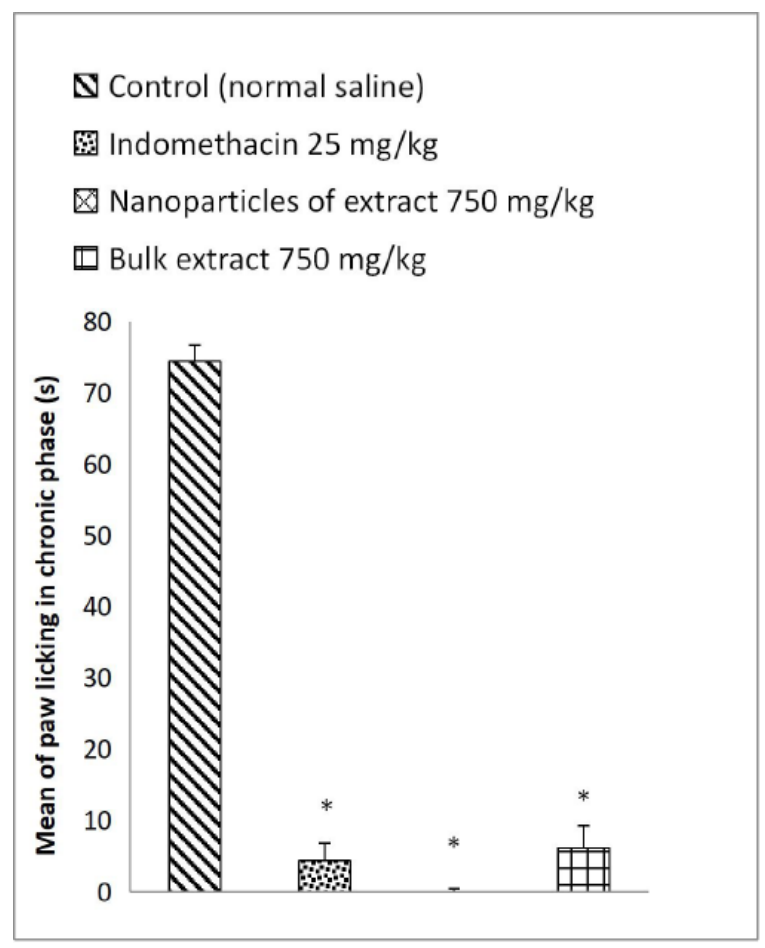

Figure 4: Effect of fruit Cordia myxa nano and bulk hydro alcoholic extracts on formalin induced inflammation in hind paw of mice. The inflammation was produced by subcutaneous injection of $0.04 \mathrm{ml}$ of $2.5 \%$ formalin in the right hind paw of the mice. Values represent the mean \pm S.E.M duration of paw licking in 15-25 min after treatments as chronic phase of inflammation, ${ }^{*} P<0.0001$ compared to control. 


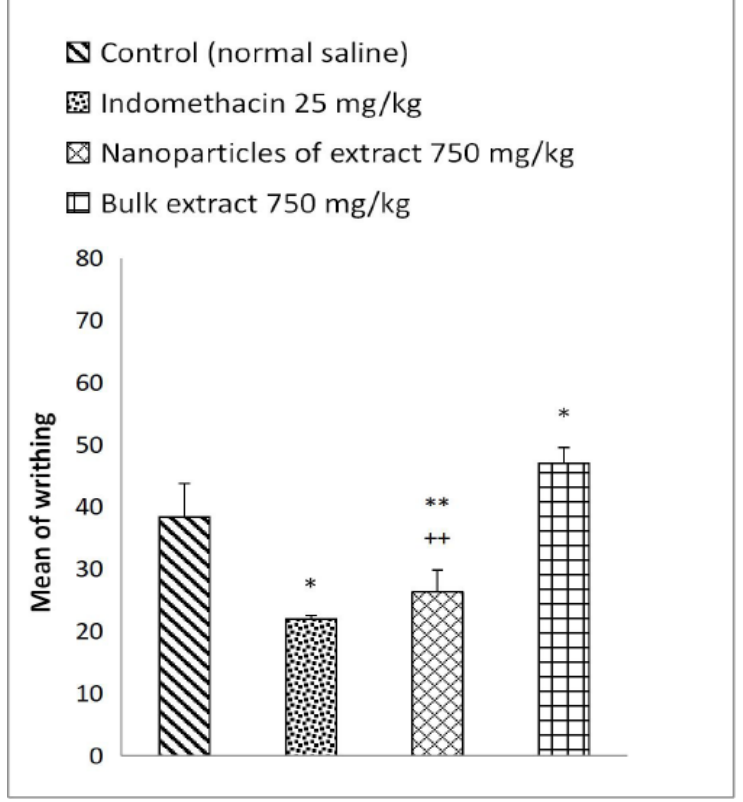

Figure 5: Effect of intraperitoneally administrated Cordia myxa fruits nano and bulk hydroalcoholic extracts on acetic acid-induced writhing in mice. The number of writhes was counted in second $10 \mathrm{~min}$ after intraperitoneally injection of $0.1 \mathrm{ml}$ of $1 \% \mathrm{v} / \mathrm{v}$ acetic acid. Values are mean \pm S.E.M of writhes in mice in second $10 \mathrm{~min}$ post acetic acid injection, ${ }^{*} P=0.0001,{ }^{* *} P=0.048$, compared to control (normal saline); ${ }^{++} P=0.002$ compared to $\mathrm{BE}$.

\section{DISCUSSION}

In the present study hydro-alcoholic extract of Cordia myxa fruit was prepared. The nano particles of extract were produced by ball-milling technique. SEM figures of extract showed the formation of nanoparticle size of extract. The ball milling technique that used in this test is a simple method that doesn't need a high temperature for process. ${ }^{30-34}$ So extract probably remains with at least changes in its constituents.

According to a study on phytochemical screening of $C$. myxa fruit extract it was concluded that the extract contains oil, glycosides, flavonoids, sterols, saponins, terpenoids, alkaloids, phenolic acids, coumarins, tannins, resins, gums and mucilage. ${ }^{35}$ Thus, it could be suggested that the antiinflammatory, analgesic and antitussive effects of the extracts may be due to their bioactive constituents specially flavonoids. The polyphenols and flavonoids in fruits may be modulated in anti-inflammatory and nociception effects.

Diabetes was induced by alloxan. Alloxan is a glucose analogue agent that uptake into the beta cells of pancreas by GLUT2 transmembrane carrier protein and accumulated in the cells. In the beta cells, alloxan can result in insulin-dependent diabetes and also by inhibition of glucokinase as glucose sensor could inhibit insulin secretion induced by glucose. ${ }^{36}$ Thereby it could be explained that hypoglycemic activity of extracts is act via another mechanisms inducing diabetes not those involved in alloxan-induced diabetes. In our study, the NPE or BE did not have effective therapeutic hypoglycemic activity. This finding is not similar other studies. In a study it was reported that the C. myxa fruit aqueous extract caused a significant reduction in blood glucose and glycated hemoglobin of diabetic rats. ${ }^{37}$ They used this extract at $500 \mathrm{mg} / \mathrm{kg}$ of rats and for 30 days. This difference may be related to kind of our extract and dosage of treatment or design of study. However, more detailed researches can judge about it.

C. myxa is an effective traditional folk medicine for the treatment of cough. Dextromethorphan is a central acting antitussive drug. ${ }^{38}$ Thus

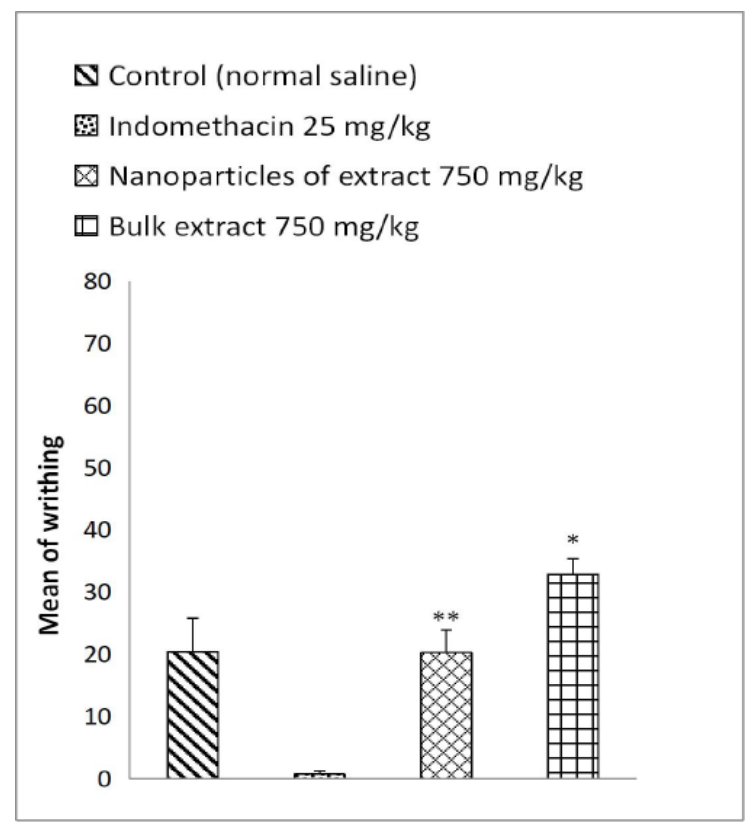

Figure 6: Effect of intraperitoneally administrated Cordia myxa fruits nano and bulk hydroalcoholic extracts on acetic acid-induced writhing in mice. The number of writhes was counted in third $10 \mathrm{~min}$ after intraperitoneally injection of $0.1 \mathrm{ml}$ of $1 \% \mathrm{v} / \mathrm{v}$ acetic acid. Values are mean \pm S.E.M of writhes in mice in the third 10 min post acetic acid injection, ${ }^{*} P=0.026$, compared to control (normal saline); ${ }^{* *} P=0.021$, compared to $\mathrm{BE}$.

it could be concluded that antitussive activity of extracts is by affecting cough center in brain. The extracts had suitable antitussive effect even better than dextromethorphan. But, NPE was not better than BE. It may be speculated that the size of particle for this extract was not to its delivery to lungs or brain for its antitussive effects. In some studies, Different extracts of C. myxa also have some properties like broncho-relaxant effect. ${ }^{15}$ This effect may be related nitric oxide modulation.

For evaluation of anti-inflammatory and analgesic activity of extracts, $2.5 \%$ formalin was injected subcutaneously in palmar surface of right hind paw in mice. In this study, Indomethacin, a non-steroidal anti-inflammatory drug, produced an inhibitory effect on the inflammation in the formalin and acetic acid tests. Indomethacin is acting as inhibitor agent of cyclooxygenase (COX) 1 and 2. COX-2 is increased by inflammatory agents like cytokines to produce elements associated with pain and inflammation like prostaglandins ${ }^{39}$ Based on a study by Hunskaar and Hole, indomethacin and other NSAIDs affect second phase in this test. ${ }^{40}$ As indomethacin can inhibit COX-2 as a NSAID, extracts may act as analgesic and anti-inflammatory agents via COX-2 mechanisms.

In the acute phase of the formalin test, both extracts were reduced paw licking but treatment with nano formulation showed a better effect than bulk extract and Indomethacin. In the chronic phase, both extracts and Indomethacin had significant difference compared the control group, but NPE could obviously reduce the number of paw licking in mice.

In the first 10 min of the acetic acid test, it was demonstrated that NPE had a better effect than BE in reducing writhings. But indomethacin showed better effect than NPE. In the third 10 min of this test, both extracts have no effect on decrease writhing induced by acetic acid. In our previous study, we demonstrated the hydro-alcoholic extract of this fruits possess analgesic and anti-inflammatory effects in formalin and acetic acid tests in mice. ${ }^{16}$ Also this finding was reported by Ficarra et al. They demonstrated that the analgesic and anti-inflammatory effects of hydro-alcoholic extract of Cordia myxa fruits is comparable with indomethacin and tramadol. ${ }^{41}$ At present our study we demonstrated the 
nano particles of C. myxa has better analgesic and anti-inflammatory effects. This may be related to better absorption or distribution and higher blood concentration.

\section{CONCLUSION}

Based on the results obtained from this study it is concluded that hydroalcoholic maceration extracts have antitussive, analgesic, acute and chronic anti-inflammatory effects in experimental mice models. However, the chemical constituents and mechanism(s) involved in pharmacological effects including measurement of active compound concentration in blood remain to be investigated. We propose the active compounds of C. myxa are isolated and each of compounds distinctively evaluated on pharmacological properties.

\section{ACKNOWLEDGEMENT}

This study is supported financially by the Research Council of the Shahid Chamran University of Ahvaz.

\section{CONFLICT OF INTEREST}

The authors declare that there are no conflicts of interest.

\section{ABBREVIATIONS}

ANOVA: One way variance analysis ; BE: Bulk extract; $C$. myxa: Cordia myxa; COX: Cyclooxygenase 1 and 2; i.p: Intraperitoneally; LSD: Least statistical differences; $\mathbf{N H}_{3}$ : Ammonium; NPE: Hydro-alcoholic extract; NSAIDs: Non-steroidal anti-inflammatory drugs; PMNLs: Polymorph nuclear lymphocytes; S.E.M: Mean \pm Standard error; SEM: The scanning electron micrographs.

\section{REFERENCES}

1. Saki J, Khademvatan S, Pazyar N, Eskandari A, Tamoradi A, Nazari P. In vitro activity of Cordia myxa Mucilage extract against Leishmania major and L. infantum promastigotes. Jundishapur J Microbiol. 2015;8(3):e19640.

2. Sanon S, Gansane A, Ouattara LP, Traore A, Ouedraogo IN, Tiono A, et al. In vitro antiplasmodial and cytotoxic properties of some medicinal plants from western Burkina Faso. Afr J Lab Med. 2013;2(1):81.

3. Abdul H NN, Al-Tahan FJ. Potentiation of the analgesic effect of mefenamic acid (Ponstan) by Cordia myxa Linn fruit. Proceeding of the 9th Veterinary Scientific Conference-Baghdad. 2009;2:180-2.

4. Al-Awadi FM, Srikumar TS, Anim JT, Khan I. Antiinflammatory effects of Cordia myxa fruit on experimentally induced colitis in rats. Nutr J. 2001;17(5):391-6.

5. Afzal M, Obuekwe C, Khan AR, Barakat H. Influence of Cordia myxa on chemically induced oxidative stress. Food Sci Nutr. 2009;39(1):6-15.

6. Keshani-Dokht S, Emam-Djomeh Z, Yarmand MS, Fathi M. Extraction, chemical composition, rheological behavior, antioxidant activity and functional properties of Cordia myxa mucilage. Int J Biol Macromol. 2018;118(Pt A):485-93.

7. Haq MA, Azam M, Hasnain A. Gum Cordia as carrier of antioxidants: Effects on lipid oxidation of peanuts. J Food Sci Tech. 2015;52(4):2366-72.

8. Abou-Shaaban RR, Al-Angari AA, El-Tahir KE, Al-Khamis KI, Mirghani OM. Comparative hypotensive and respiratory stimulation effects of ripe and unripe fruit mucilage of Cordia myxa and Cordia obliqua in guineapigs and rabbits. Phytother Res. 1989;3(4):126-31.

9. Ali WR, Al-Asady ZT, Ibrahim AA. Immunomodulatory of Cordia myxa (L.) aqueous extract fruit in immunized mice with hydatid cyst fluid. J Nat Sci Res. 2015;5(10):75-83.

10. Ad-Dahhan HA. Detection of Immunomodulatory activity of alcoholic extract of Cordia myxa (L.) fruit. J Al-qadisiyah Pure Sci. 2010;15(4):14-21.

11. Ashour OM, Abdel-Naim AB, Abdallah HM, Nagy AA, Mohamadin AM, AbdelSattar EA. Evaluation of the potential cardioprotective activity of some Saudi plants against doxorubicin toxicity. Z Naturforsch C. 2012;67(5-6):297-307.

12. Afzal M, Obuekwe $C$, Khan AR, Barakat H. Antioxidant activity of Cordia myxa L. and its hepatoprotective potential. EJEAF Che. 2007;8(6):2236-42.

13. Pandey B, Deshpande B, Singh S, Chandrakar V. Estimation of elemental contents of Cordia myxa and its antimicrobial activity against various pathogenic microorganisms. Indian J Sci Res. 2014;4(1):39-44

14. Rashed K, Luo MT, Zhang LT, Zheng YT. Evaluation of anti-HIV-1 activity of Cor dia myxa L. and phytochemical profile. Banats J Biotechnol. 2015;5(10):75-82.

15. AlBayaty MA, AlTahan FJ. Mechanism of the tracheal smooth muscle relaxant activity of the Cordia myxa plant extract in sheep. Iraqi J Vet Sci. 2008:32(2):21426.

16. Ranjbar M, Varzi HN, Sabbagh A, Bolooki A, Sazmand A. Study on Analgesic and Anti-inflammatory Properties of Cordia myxa Fruit Hydro-alcoholic Extract. PJBS. 2013;16(24):2066-9

17. Ahamed M, AISalhi MS, Siddiqui MK. Silver nanoparticle applications and human health. Clin Chim Acta J. 2010;411(23-24):1841-8.

18. Scott NR. Nanotechnology and animal health. Rev Sci Tech-Off Int Epiz. 2005;24(1):425-32.

19. Puckett SD, Taylor E, Raimondo T, Webster TJ. The relationship between the nanostructure of titanium surfaces and bacterial attachment. Biomaterials. 2010;31(4):706-13.

20. Seigneuric R, Markey L, Nuyten SAD, Dubernet C, Evelo TAC, Finot E, et al. From nanotechnology to nanomedicine: Applications to cancer research. Curr Mol Med. 2010;10(7):640-52.

21. Ventola $\mathrm{CL}$. The nanomedicine revolution: Part 1: Emerging concepts. Pharm Ther. 2012;37(9):512-7.

22. Galvin P, Thompson D, Ryan KB, McCarthy A, Moore AC, Burke CS, et al. Nanoparticle-based drug delivery: Case studies for cancer and cardiovascula applications. Cell Mol Life Sci. 2012;69(3):389-404.

23. Poirot-Mazères I. Legal aspects of the risks raised by nanotechnologies in the field of medicine. J Int Bioethique. 2011;22(1):99-118.

24. Jimenez-Suarez $V$, Nieto-Camacho A, Jiménez-Estrada M, Alvarado SB. Antiinflammatory, free radical scavenging and alpha-glucosidase inhibitory activities of Hamelia patens and its chemical constituents. Pharm Biol. 2016;54(9):1822 30.

25. Loh ZH, Samanta AK, Wan SHP. Overview of milling techniques for improving the solubility of poorly water-soluble drugs. Asian J Pharm Sci. 2015;19(4):25574.

26. Syiem D, Syngai G, Khup PZ, Khongwir BS, Kharbuli B, Kayang H. Hypoglycemic effects of Potentilla fulgens $L$. in normal and alloxan-induced diabetic mice. J Ethnopharmacol. 2002;83(1-2):55-61.

27. Silva CJ, Bastos JK, Takahashi CS. Evaluation of the genotoxic and cytotoxic effects of crude extracts of Cordia ecalyculata and Echinodorus grandiflorus. J Ethnopharmacol. 2010;127(2):445-50.

28. Li ZY, Zhi HJ, Xue SY, Sun HF, Zhang FS, Jia JP, et al. Metabolomic profiling of the flower bud and rachis of Tussilago farfara with antitussive and expectorant effects on mice. J Ethnopharmacol. 2012;140(1):83-90.

29. Vogel HG, Vogel WH. Drug discovery and evaluation, pharmacological assay Springer Science and Business Media.1997;360-82.

30. Damonte LC, Zélis LM, Soucase BM, Fenollosa MH. Nanoparticles of ZnO obtained by mechanical milling. Powder Technol. 2004;148(1):15-9.

31. Ozdemir I, Ahrens S, Mücklich S, Wielage B. Nanocrystalline Al Al2O3p and SiCp composites produced by high-energy ball milling. J Mater Process Technol. 2008;205(1-3):111-8.

32. Lee JS, Park K, Kang MI, Park IW, Kim SW, Cho WK, et al. ZnO nanomaterials synthesized from thermal evaporation of ball-milled $\mathrm{ZnO}$ powders. J Cryst Growth. 2003; 254(3-4):423-31.

33. Damontea LC, Donderis V, Hernndez-Fenollosa MA. Trivalent dopants on ZnO semiconductor obtained by mechanical milling. J Alloy Compd. 2009;483(13):442-4.

34. Glushenkov AM, Zhang HZ, Chen Y. Reactive ball milling to produce nanocrystalline ZnO. Mater Lett. 2008;62(24):4047-9.

35. Al-Snafi AE. The Pharmacological and therapeutic importance of Cordia myxa-A review. IOSR J Pharm. 2016;6(6):47-57.

36. Lenzen S. The mechanisms of alloxan-and streptozotocin-induced diabetes. Diabetologia. 2008;51(2):216-26.

37. Nasab FY, Hajinezhad MR, Hashemi H, Miri A. Comparative study of antidiabetic activity of two herbal extracts in alloxan-induced diabetic rats. Orient Pharm Exp Med. 2017;17(3):291-5.

38. Bolser DC. Mechanisms of action of central and peripheral antitussive drugs. Pulm Pharmacol Ther. 1996;9(5-6):357-64.

39. Vane JR, Botting RM. Anti-inflammatory drugs and their mechanism of action Inflamm Res. 1998;47(2):78-87.

40. Hunskaar S, Hole K. The formalin test in mice: Dissociation between inflammatory and non-inflammatory pain. Pain. 1987;30(1):103-14.

41. Ficarra R, Ficarra P, Tommasini S, Calabro ML, Ragusa S, Barbera R, et al. Leaf extracts of some Cordia species: Analgesic and anti-inflammatory activity as well as their chromatographic analysis. Farmaco. 1995;50(4):245-56. 